\title{
Decisiones administrativas automatizadas en materia social: algoritmos en la gestión de la Seguridad Social y en el procedimiento sancionador
}

\author{
Algorithm-assisted decision-making in the social matters: \\ management of Social Security and administrative \\ sanctioning procedure
}

\author{
José María Goerlich Peset \\ Catedrático Derecho del Trabajo y la Seguridad Social \\ Universidad de Valencia
}

ORCID ID: 0000-0002-2910-2153

Recibido: 3/5/2021

Aceptado: 7/5/2021

doi: https://doi.org/10.20318/labos.2021.6215

\begin{abstract}
Resumen: $\quad$ El recientemente aprobado Real Decreto-Ley 2/2021 extiende el campo de las actuaciones administrativas automatizadas a la mayor parte de la gestión de la Seguridad Social y las introduce en el procedimiento sancionador en el orden social. En este nuevo contexto, se intenta contextualizar estas novedades, analizando sus precedentes, $y$, sobre todo, determinar los problemas interpretativos que plantean. En este último terreno, se dispensa una atención especial a las garantías que los ciudadanos tienen en relación con este tipo de decisiones automatizadas.

Palabras clave: decisiones automatizadas, actuaciones administrativas automatizadas, inspección de trabajo, gestión de la seguridad social.
\end{abstract}

Abstract: $\quad$ The recently approved Royal Decree-Law 2/2021 extends the field of automated administrative actions to most of the management of Social Security and introduces them in the sanctioning procedure in the social order. In this new context, an attempt is made to contextualize these novelties, analyzing their precedents, and, above all, to determine the interpretative problems they raise. In the latter field, special attention is paid to the guarantees that citizens have in relation to this type of automated decisions.

Keywords: $\quad$ automated decisions, automated administrative actions, labor inspection, social security management.

\section{Las decisiones automatizadas en el RDL 2/2021}

Dentro de los sucesivos hallazgos temáticos relacionados con el impacto de la digitalización en las relaciones laborales, la doctrina jurídico-laboral ha centrado su atención últimamente en las decisiones automatizadas. El desarrollo de la inteligencia artificial y el tratamiento del Big Data posi-

*jose.m.goerlich@uv.es 
bilita que se extiendan este tipo de decisiones, adoptadas por algoritmos cada día más complejos. Por supuesto, el descubrimiento de sus potenciales en diferentes facetas de la gestión de personal ha hecho que los iuslaboralistas hayamos vuelto nuestra atención hacia el tema. La doctrina sobre este particular se ha incrementado en los últimos tiempos ${ }^{1}$, si bien se ha centrado sobre todo en los límites de su utilización por el empresario con la finalidad de respetar los derechos de los trabajadores. Ahora bien, la temática tiene otras facetas, alguna de las cuales es sumamente importante. $\mathrm{Me}$ refiero a su posible utilización por las entidades administrativas que desarrollan su actividad en el ámbito social. Como veremos de inmediato, hace ya más de una década que este tipo de decisiones está presente en nuestra legislación de Seguridad Social. Pero, a diferencia de lo que ocurre entre los administrativistas, que llevan tiempo dedicando su esfuerzo a la reflexión sobre esta cuestión, ello ha pasado relativamente inadvertido entre nosotros.

Creo que esta situación cambiará en el corto plazo como consecuencia de la aprobación del Real Decreto-ley 2/2021, de 26 de enero, de refuerzo y consolidación de medidas sociales en defensa del empleo. Ha llamado mucho la atención, en efecto, la incorporación de un nuevo párrafo al art. 53.1.a) LISOS por la DF 4a RDL 2/2021 que da por supuesta la existencia de actas de inspección "extendidas en el marco de actuaciones administrativas automatizadas". Pero el alcance de la reforma en este aspecto es más amplio, puesto que afecta también a la gestión de la Seguridad Social: además de la citada modificación de la LISOS que tanto ha llamado la atención, la DF 5a RDL 2/2021 ha introducido una extensa reforma de la LGSS que afecta a la tramitación de los procedimientos administrativos por las entidades gestoras ya que "la situación de pandemia ha puesto de manifiesto las deficiencias existentes" en ella. En este marco se da nueva redacción al art. 130 LGSS, ampliando los supuestos en los que aquellas pueden recurrir a la utilización de procedimientos administrativos automatizados.

Previamente, el RDL 2/2021 procede a incrementar el volumen de información a disposición de las entidades gestoras de la Seguridad Social y de la Inspección de Trabajo y facilita su tratamiento. Implica, en esta línea, una ampliación de los sujetos obligados a suministrar información, las finalidades para las que puede ser utilizada y la forma de acceso a la misma². Se busca, en pocas pala-

${ }^{1}$ Véanse, sobre el particular, entre otros, TODOLÍ SIGNES, A., "La gobernanza colectiva de la protección de datos en las relaciones laborales: «big data», creación de perfiles, decisiones empresariales automatizadas y los derechos colectivos", Revista de derecho social, 84 (2018), pp. 69 ss, SÁEZ LARA, C., "Algoritmos y discriminación en el empleo: un reto para la normativa antidiscriminatoria", Nueva revista española de derecho del trabajo, 232(2020), pp. 83 ss., y "El algoritmo como protagonista de la relación laboral. Un análisis desde la perspectiva de la prohibición de discriminación”, Temas laborales 155 (2020), pp. 41 ss., ÁLVAREZ CUESTA, H., El impacto de la inteligencia artificial en el trabajo: desafíos y propuestas, Cizur Menor (Thomson Reuters/Aranzadi), 2020, MERCADER UGUINA J.R., "Algoritmos: personas y números en el Derecho Digital del trabajo", La Ley, No 48, Sección Ciberderecho, 24 de febrero de 2021; MOLINA NAVARRETE, C., “Duelo al sol» (digital). ¿Un algoritmo controla mi trabajo? Sí; a tu empresa también”, Revista de Trabajo y Seguridad Social, CEF, 457 (abril 2021), pp. 5 ss.

${ }^{2} \mathrm{La}$ amplia reforma de la LGSS por la DF 5a RDL 2/2021 incluye, en primer lugar, la ampliación del número de potenciales obligados a suministrar información a las Entidades Gestoras, hasta convertirlo aparentemente en universal. Si anteriormente, y de acuerdo con su rúbrica, el art. 40 LGSS establecía un "deber de información por entidades financieras, funcionarios públicos, profesionales oficiales y autoridades", ahora el mismo se imputa a "las personas y entidades sin personalidad, entidades financieras, funcionarios públicos, profesionales oficiales y autoridades". Desde una perspectiva finalista, se camina igualmente hacia una universalización del uso de la información debida. La redacción anterior de los preceptos reformados delimitaba su alcance sobre la base de su necesidad para la función recaudatoria (cfr. arts. 40.4 y 40.6 LGSS). En la nueva, se establece un vínculo más laxo -"especialmente en el ámbito de la liquidación, control de la cotización y de recaudación de los recursos de la Seguridad Social y demás conceptos de recaudación conjunta" (art. 40.1, 40.4, 40.6 o 40.7)-; y, además, se presta particular atención al control de las ayudas o subvenciones dispensadas por las entidades gestoras (últimos párrafos ańadidos a art. 71.1 letras a] y h]). En términos de procedimiento, por último, se avanza en relación con los instrumentos para el cumplimiento de las obligaciones informativas. Las normas vigentes hasta el RDL 2/2021 ya hacían referencia a que las obligaciones informativas o de 
bras, poner a su disposición más datos, hacerlos más fácilmente accesibles y, sobre todo, susceptibles de una mayor utilización. En este último sentido, cabe traer a colación la reforma del art. 77 LGSS, sobre "reserva de datos", en el que se advierte una ampliación de los supuestos excepcionales en los que la Administración de la Seguridad Social puede proceder a su cesión o comunicación a terceros. Antes del RDL 2/2021, los terceros considerados por el precepto eran ocho; ahora, son ¡catorce! Y el primero que se añade es el Organismo Estatal Inspección de Trabajo y Seguridad Social que "tendrá acceso directo a los datos, informes y antecedentes obtenidos por la Administración de la Seguridad Social en el ejercicio de sus funciones, que resulten necesarios para la preparación y ejercicio de sus funciones de inspección" (art. 77.1.i] LGSS).

Por supuesto, el aumento de la cantidad de información a disposición de las entidades administrativas implicadas incrementa sus posibilidades de actuación algorítmica. De hecho, como he indicado, el RDL 2/2021 las amplia en el marco de la gestión de la Seguridad Social y las introduce formalmente en el marco del procedimiento sancionador en el orden social. La utilización de algoritmos en los dos ámbitos a los que afecta la regulación del RDL 2/2021 no es estrictamente una novedad. De hecho, las reglas que se contienen en este no son sino la culminación, por ahora, de una evolución que arranca de las dos décadas inmediatamente anteriores. Estamos asistiendo en definitiva a una transición digital de la administración laboral y de seguridad social, que va dejando sus huellas en la normativa aplicable. Por lo que se refiere a la gestión de la Seguridad Social, los comienzos de la digitalización han de ubicarse a mediados de la década de los 90, cuando, sobre la base de la "abierta incorporación de las técnicas informáticas y telemáticas en la relación ciudadanoAdministración" que había preconizado la Ley 30/1992, de 26 de noviembre, de Régimen Jurídico de las Administraciones Públicas y del Procedimiento Administrativo Común, se dictó la Orden de 3 de abril de 1995 sobre uso de medios electrónicos, informáticos y telemáticos en relación con la inscripción de empresas, afiliación, altas y bajas de trabajadores, cotización y recaudación en el ámbito de la Seguridad Social. Desde entonces la incorporación de innovaciones en las diferentes áreas de la gestión se ha producido sin cesar en un proceso que la Asociación Internacional de Seguridad Social ha calificado como una "historia de éxito" en $2016^{3}$. En el ámbito de la garantía administrativa de las normas laborales y de Seguridad Social, la importancia creciente de la digitalización se refleja nítidamente en la definición del sistema de Inspección de Trabajo y Seguridad Social. El art. 1.1 Ley 23/2015, de 21 de julio, Ordenadora del sistema de Inspección de Trabajo y Seguridad Social -en adelante, LITSS-, integra en él, como hacía su precedente inmediato, el art. 1.1 Ley 42/1997, "el conjunto de principios legales, normas, órganos, funcionarios y medios materiales" que persiguen la consecución de sus finalidades. Pero, entre estos últimos incluye específicamente "los informáticos". Por supuesto, la incorporación de recursos informáticos y de técnicas de tratamiento masivo de datos a la lucha contra el fraude laboral y de seguridad social se había venido produciendo con anterioridad

cesión de datos se habían de instrumentar "preferentemente por medios electrónicos". Ahora se añade que "la Administración de la Seguridad Social podrá recabar a través de sus redes corporativas o mediante consulta a las plataformas de intermediación de datos u otros sistemas habilitados al efecto, los datos o la información necesaria para la tramitación de los procedimientos que resulten de su competencia" (art. 40.6 LGSS).

${ }^{3}$ Asociación Internacional de Seguridad Social, 10 desafios mundiales para la Seguridad Social, 2016 https://www. issa.int/html/10/images/ISSA-Report-Panama-2016-es.pdf (consulta 18 marzo 2021). Detalles de esta evolución en RINCÓN MIRÓN, J.A., "La implantación de los procedimientos electrónicos en la Seguridad Social (2013-2016)”, Revista de Ministerio de Empleo y Seguridad Social, número extraordinario Politicas de empleo y Seguridad Social en la X Legislatura 2016, pp. 121 ss., o GOERLICH PESET, J.M., "Digitalización, robotización y protección social”, TeoríaSDerecho, 23(2018) pp. 108 ss. Para un análisis jurídico-positivo del estado de la situación, MERCADER UGUINA, J.R., Los procedimientos administrativos en materia de Seguridad Social, Thomson Reuters/Aranzadi, Cizur Menor, 2017, pp. 129 ss. 
a la aprobación del texto de $2015^{4}$ y ha dejado huella también en los sucesivos planes de actuación de la ITSS que se han hecho públicos después, así como en otras disposiciones 5 .

El RDL 2/2021 da un paso más en ambas evoluciones, ampliando la presencia de los algoritmos administrativos en el ámbito social. En este contexto, mi objetivo es doble. Intento, de un lado, ubicar las nuevas reglas en el conjunto del sistema, analizando su origen y los principales problemas interpretativos que plantean. Aspiro, de otro y sobre todo, a reflexionar sobre las garantías en su utilización. En este sentido, no puede perderse de vista que, si bien es cierto que la utilización de los recursos digitales por los entes públicos ha de redundar forzosamente en la mejora de su eficiencia y, por tanto, en una mayor protección de los intereses públicos en juego, no lo es menos que la presencia de la inteligencia artificial en este ámbito no por ello deja de implicar la presencia de riesgos elevados. Así ha sido puesto de manifiesto, con los matices que se quiera, en el Libro Blanco aprobado por la Comisión europea el año pasado ${ }^{6}$

\section{Extensión de las decisiones automatizadas a la gestión recaudatoria de la Seguridad Social}

La presencia en la normativa de Seguridad Social de decisiones automatizadas se remonta a 2009, cuando el RDL 10/2009, de 13 de agosto, por el que se regula el programa temporal de protección por desempleo e inserción, añadió al texto refundido de la LGSS entonces vigente una disp. adic. 46a , sobre "tramitación electrónica de procedimientos en materia de protección por desempleo". Esta disposición, se proyectaba las normas generales sobre procedimientos administrativos automatizados (Ley 11/2007, de 22 de junio, de acceso electrónico de los ciudadanos a los Servicios

${ }^{4}$ Referencias en GOERLICH PESET, J.M., "Lucha contra el empleo irregular y el fraude en la Seguridad Social”, Revista de Ministerio de Empleo y Seguridad Social, número extraordinario Políticas de empleo y Seguridad Social en la X Legislatura, 2016, pp. 150 ss.

${ }^{5}$ El Plan Estratégico de la Inspección de Trabajo y Seguridad Social para el período 2018-2020, aprobado por Acuerdo del Consejo de Ministros de 6 de abril de 2018 (BOE 19 de abril de 2018) contenía un "objetivo 4” dirigido a "mejorar el Sistema de Información y los medios materiales a disposición de la Inspección”. Las líneas 32 ss. incluyen toda una seria de actuaciones en el terreno de la digitalización entre la que destaca la previsión sobre la "Herramienta de Lucha contra el Fraude", instrumento informático "de carácter predictivo que, mediante el acceso a un conjunto de bases de datos, permita a la Inspección definir, gestionar y visualizar reglas y patrones de fraude mediante modelos avanzados de gestión intensiva de la información disponible” (línea 33). A su través, es posible mejorar sustancialmente la "planificación y programación de la actividad inspectora" a la que se refiere la línea 33.

Además, estas técnicas basadas en el Big Data han posibilitado determinadas actuaciones directas sobre las situaciones de irregularidad. Los Planes de choque desarrollados en el marco del Plan director por un trabajo digno (20182019-2020) -Acuerdo del Consejo de Ministros de 27 de julio de 2018, BOE 28 julio- son una muestra de ello. Han implicado la comunicación directa entre la ITSS y las empresas en relación con las posibles situaciones de irregularidad mediante el tratamiento masivo de la información, "informándoles de los datos obtenidos, instándoles a revisar su situación, y advirtiéndoles de la realización de actuaciones inspectoras de comprobación en caso de no regularización” en el plazo de un mes.

En fin, cabe traer a colación la Orden TMS/667/2019, de 5 de junio, por la que se crea el Observatorio para la lucha contra el fraude a la Seguridad Social, le asigna como "objetivos", entre otros, "proponer la realización de estudios y análisis de datos en el ámbito de la afiliación, cotización y recaudación para identificar posibles conductas irregulares y de fraude, con especial atención a las que tengan repercusión en el régimen económico de la Seguridad Social” y "promover acciones y medidas dirigidas a la prevención del fraude a la Seguridad Social derivadas de los estudios de comportamiento y análisis de los datos disponibles" (art. 3, c] y d]).

Para una valoración de la eficacia del uso de estas técnicas predictivas, TODOLÍ SIGNES, A., "Retos legales del uso del big data en la selección de sujetos a investigar por la Inspección de Trabajo y de la Seguridad Social”, Revista Galega de Administración Pública, 59 (2020), pp. 313 ss.

${ }^{6}$ Libro blanco sobre la inteligencia artificial: un enfoque europeo orientado a la excelencia y la confianza, 19 febrero 2020, $\operatorname{COM}(2020) 65$ final, pp. 21 ss. 
Públicos) a "los procedimientos de gestión de la protección por desempleo previstos en el título III de esta Ley”. En este sentido, el párrafo $2^{\circ}$ encomendaba a la Dirección General del Servicio Público de Empleo Estatal las misiones de determinar, en la línea de la exigencia del art. 38.2 Ley 11/2007, "el procedimiento o procedimientos de que se trate"; y, en sintonía literal con las previsiones de su art. 39, la de establecer, "el órgano u órganos competentes, según los casos, para la definición de las especificaciones, programación, mantenimiento, supervisión y control de calidad y, en su caso, auditoría del sistema de información y de su código fuente. Asimismo, se indicará el órgano que debe ser considerado responsable a efectos de impugnación"7.

Con posterioridad, la Ley 34/2014, de 26 de diciembre, de medidas en materia de liquidación e ingreso de cuotas de la Seguridad Social, modificó la mencionada disposición adicional y amplió la posibilidad de tramitación automatizada a la gestión del conjunto de las prestaciones, "excluidas las pensiones en su modalidad no contributiva". La reforma de 2014 afectó así al título del precepto y al posible objeto de las decisiones automatizadas y supuso una ampliación de las autoridades facultadas para determinar los procedimientos y establecer los órganos competentes: junto al Director General del Servicio Público de Empleo Estatal, se incluían los Directores Generales del Instituto Nacional de la Seguridad Social y del Instituto Social de la Marina. Esta redacción fue incorporada poco después al art. 130 del nuevo Texto Refundido de $2015^{8}$.

Es este precepto el que ha sido modificado por la disp. final 5a RDL 2/2021 que, con respecto a la versión precedente, introduce tres novedades. De entrada, desaparece la remisión a la Ley 11/2007. Dado que fue derogada, aun con matices, por la Ley 39/2015, de 1 de octubre, del Procedimiento Administrativo Común de las Administraciones Públicas (cfr. disp. der. única, apartado 2), la nueva redacción del art. 130 LGSS remite ahora al art. art. 41.1 Ley 40/2015, de 1 de octubre, de Régimen Jurídico del Sector Público. En segundo lugar, y sobre todo, se amplia el ámbito de aplicación al conjunto de la gestión de la Seguridad Social: si desde 2014, la rúbrica del precepto se refería a la "tramitación electrónica de procedimientos en materia de prestaciones”, desde el RDL 2/2021 alude a la "tramitación electrónica de procedimientos en materia de Seguridad Social". De este modo, también "los procedimientos de afiliación, cotización y recaudación" pasan a formar parte de aquellos en los que "podrán adoptarse y notificarse resoluciones de forma automatizada". En fin, como lógica consecuencia de esta ampliación, la Dirección General de la Tesorería General de la Seguridad Social pasa a estar entre las autoridades que pueden delimitar los procedimientos que se automatizan y los órganos competentes para las diferentes funciones a las que se refiere el segundo párrafo del art. 130 LGSS.

A la vista del contenido del art. 130 LGSS, tanto en su redacción actual como en las precedentes, se observa su claro alineamiento con las normas administrativas comunes. En este sentido, no se advierte desviación significativa con respecto a las previsiones del art. 41 Ley 40/2015 -y, antes, de los arts. 38 y 39 Ley 11/2007-. La única diferencia con las reglas administrativas se encuentra en que se concretan las materias a las que puede extenderse la gestión automatizada y se designan las autoridades competentes para determinar los procedimientos y los órganos que gestionan el algoritmo. Habida cuenta la falta de originalidad de la solución, es posible que la presencia de una regla específica en la Ley General de la Seguridad Social se relacione con los problemas históricos respecto

${ }^{7}$ En ejecución del precepto, se dictaron Resoluciones de 15 de octubre de 2009, del Servicio Público de Empleo Estatal, que procedió a regular "la tramitación electrónica automatizada de diversos procedimientos en materia de protección por desempleo" (BOE 17 octubre), y de 12 de julio de 2010, del Instituto Social de la Marina y del Servicio Público de Empleo Estatal, por la que se regula la tramitación electrónica automatizada de diversos procedimientos en materia de protección por desempleo del Régimen Especial de los Trabajadores del Mar (BOE 16 septiembre)

${ }^{8}$ En ejecución véase Resolución de 23 de febrero de 2016, del Instituto Nacional de la Seguridad Social, por la que se regula la tramitación electrónica automatizada de diversos procedimientos de gestión de determinadas prestaciones del sistema de la Seguridad Social (BOE 1 de marzo). 
de la aplicación de las reglas generales del procedimiento administrativo común en este ámbito9 . Lo bien cierto es, sin embargo, que, en rigor, resulta completamente innecesaria. Es verdad que la Ley 39/2015 de 1 de octubre, del Procedimiento Administrativo Común de las Administraciones Públicas, sigue reconociendo la prevalencia de la normativa específica en relación con "las actuaciones y procedimientos de gestión, inspección, liquidación, recaudación, impugnación y revisión en materia de Seguridad Social y Desempleo" (disp. adic. 1a.2.b]). Pero también lo es que las reglas sobre gestión automatizada de los procedimientos administrativos se encuentran ahora en Ley 40/2015, de 1 de octubre, de Régimen Jurídico del Sector Público, que, con carácter general, resulta aplicable a las entidades gestoras y servicios comunes, a través de su equiparación a organismos autónomos, con las salvedades establecidas en su disp. adic. 13a , que no parecen extenderse al aspecto que nos ocupa. En este contexto, el art. 130 LGSS parece tener un papel estrictamente "declarativo», en el sentido de que, incluso si no existiera, las actuaciones administrativas automatizadas serían igualmente posibles en el marco de la legislación administrativa general. Su única relevancia real se encuentra, según creo, en la prohibición de utilizarlas en relación con las pensiones no contributivas, que ha persistido en las sucesivas redacciones del precepto desde 2009.

\section{Algoritmos en el procedimiento administrativo sancionador en el orden social}

Por lo que se refiere a la reforma de la LISOS introducida por la DF $4^{\mathrm{a}} \mathrm{RDL} 2 / 2021$, persigue según la Exposición de Motivos, "la adecuación del procedimiento administrativo sancionador en el orden social a las posibilidades que las nuevas tecnologías permiten, a través de un procedimiento especial iniciado mediante la extensión de actas de infracción automatizadas, es decir, sin intervención directa de un funcionario actuante en su emisión y sin reducción de las garantías jurídicas de los administrados". Lo primero se consigue claramente puesto que la nueva redacción del art. 53.1.a) LISOS da carta de naturaleza a las nuevas "actas extendidas en el marco de actuaciones administrativas automatizadas", que permitirá iniciar procedimientos administrativos sancionadores conforme a las reglas generales (cfr. art. 52.1.a] ET). Lo que no tengo tan claro es que su introducción no suponga algún tipo de "reducción de las garantías jurídicas de los administrados", aunque sea solo porque la regulación del RDL 2/2021 no incluye regulación alguna para estas nuevas actas, lo que abre problemas importantes de inserción en el sistema preexistente.

\subsection{Las nuevas "actas extendidas en el marco de actuaciones administrativas automatizadas"...}

Conviene observar, de entrada, que el RDL 2/2021 no ha establecido una regla similar a la prevenida en el ya examinado art. 130 LGSS en el ámbito de la gestión de la Seguridad Social. En línea con lo que acabamos de ver, el legislador ha considerado probablemente que, aunque la aplicación de las reglas sobre procedimiento administrativo común sea en este ámbito también subsidiaria (cfr. art. 51 LISOS y disp. adic. $1^{\text {a }}$.2.c] Ley 39/2015), las reglas generales de los arts. 41 y 42 Ley 40/2015 son directamente aplicables a la actividad de la Inspección. Ello ha permitido orillar la introducción de una norma similar al art. 130 LGSS en la LISOS o en la LITSS. Se ha preferido confiar la determinación de autoridades y procedimientos a una futura modificación del Reglamento general sobre procedimientos para la imposición de sanciones por infracciones de Orden Social y para los expedientes liquidatorios de cuotas de la Seguridad Social -en adelante, RGPSOS-, cuya tramitación se encuen-

\footnotetext{
${ }^{9}$ Cfr., extensamente, MERCADER, Los procedimientos administrativos cit., pp. 71 ss.
} 
tra en marcha desde antes de la publicación del RDL 2/2021 ${ }^{10}$. En este sentido, el proyectado art. 43 RGPSOS $^{11}$ encomienda al Organismo Estatal Inspección de Trabajo y Seguridad la generación a través de su sistema de información, mediante actuaciones administrativas automatizadas de "las actas de infracción que resulten pertinentes en virtud de los datos, antecedentes e informes que obren en el mismo, así como en las bases de datos de las entidades que le prestan su auxilio y colaboración".

En este contexto, lo único que hace el RDL 2/2021 es incorporar la posibilidad de que las actas de infracción sean "extendidas en el marco de actuaciones administrativas automatizadas", en los términos del art. 53.1.a], segundo párrafo, LISOS. Se ha señalado que la introducción de esta regla de rango legal evita la colisión de este tipo de actuaciones con la reserva de la extensión de actas a los funcionarios integrados en la Inspección de Trabajo (art. 22.5 Ley 23/2015, de 21 de julio, Ordenadora del Sistema de Inspección de Trabajo y Seguridad Social), que tendría como lógica consecuencia la imposibilidad de iniciación de cualquier procedimiento sancionador sin intervención de estos (art. 52.1.a] LISOS) ${ }^{12}$. Esta idea viene confirmada en las ya aludidas actuaciones preparatorias de la modificación del RGPSOS. De aprobarse el proyecto de Decreto, se incorporaría al indicado Reglamento General un capítulo IV, titulado "Del procedimiento sancionador promovido por actuación administrativa automatizada en el ámbito de la Administración General del Estado". Los futuros preceptos muestran que las actas extendidas como consecuencia de una actuación administrativa automatizada agotan por lo general sus efectos en la iniciación del procedimiento sancionador; y únicamente despliegan efectos adicionales en los casos en los que no se formulan alegaciones frente a ellas, en los que la propuesta de resolución se genera también de forma automatizada (art. 43). Por el contrario, cuando el interesado formula "alegaciones en las que se invoquen hechos o circunstancias distintas a los consignados en las actas, insuficiencia del relato fáctico de la mismas, o indefensión por cualquier causa, deberán asignarse los expedientes a un actuante con funciones inspectoras, para que informe sobre las mismas"; y, a partir de este momento, el procedimiento sigue conforme a las reglas generales (art. 46.3).

A la vista del limitado papel que se asigna a las nuevas actas automatizadas, cabría minusvalorar la importancia de la innovación. Creo, sin embargo, que tiene una trascendencia de primer orden. En este sentido, no se está limitando a trasladar a las infracciones del orden social instrumentos que existen en otros sectores de la actividad administrativa sancionadora. Al contrario, la reforma introducida por el RDL 2/2021 resulta ser pionera: no existen normas legales similares, y ni siguiera se cuenta con ello en el terreno de las oportunidades relacionadas con la automatización. De hecho, aunque la tramitación automatizada se ha incorporado hace tiempo a las infracciones de tráfico constatadas mediante dispositivos de control de imagen y velocidad, la doctrina jurídicoadministrativa se limita a poner la selección de objetivos y la detección del fraude como ejemplo del posible papel de algoritmos y big data en el campo sancionador ${ }^{13}$. Por eso, no deja de extrañar la

${ }^{10}$ De acuerdo con la web del Ministerio, el trámite de audiencia e información pública se produjo entre los días 18 y 27 de enero de 2021 (cfr. https://www.mites.gob.es/es/participacion/informaciones/historico-informacion/index.htm: acceso 16 marzo 2021).

${ }^{11} \mathrm{El}$ indicado borrador, de fecha 16 de enero de 2021, puede encontrarse en https://www.mites.gob.es/ficheros/participacion/historico/informacion-publica/2021/Proyecto-RD-sancionesSS_20210118.pdf (acceso: 16 marzo 2021).

${ }^{12}$ IZQUIERDO, M., "La IA en la inspección y sanción de irregularidades en las ayudas sociales y seguridad social", ponencia en el Congreso (webinar), Regulación y explotación de big data para los servicios públicos (2, 9 y 16 de marzo 2021), puede verse en https://www.youtube.com/watch?v=5OGj7TiQQ_0 (acceso 25 de marzo de 2021), aproximadamente desde 19' 50".

${ }^{13}$ Cfr. CERRILLO MARTÍNEZ, A., "El impacto de la inteligencia artificial en el Derecho Administrativo. ¿Nuevos conceptos para nuevas realidades técnicas?", Revista General de Derecho Administrativo 50 (2019), pp. 6 ss. o CORTÉS, O., "Algoritmos y algunos retos jurídico-institucionales para su aplicación en la Administración Pública”, Revista Vasca de Gestión de Personas y Organizaciones Públicas, 18(2020), pp. 56 ss. 
alegría con la que la novedad se ha introducido, sin reparar en los claros problemas que plantea su ubicación en el conjunto del sistema del procedimiento sancionador en el orden social, que explican seguramente la hostil recepción que con la que ha sido acogida por una parte de los profesionales del sistema de la Inspección de Trabajo ${ }^{14}$.

\section{2. ... y sus problemas interpretativos}

Por otro lado, la brusca irrupción de las decisiones automatizadas en el procedimiento sancionador plantea algunos problemas de envergadura relacionados con el papel que están llamadas a desarrollar. Nada se dice, en primer lugar, respecto del ámbito sustantivo en el que puede recurrirse a ellas. Ni el RDL 2/2021 ni los trabajos preparatorios de la reforma del RGPSOS delimitan el terreno en el que caben procedimientos automatizados. Cabe pensar en la existencia de una estrecha conexión entre la recaudación de la Seguridad Social y la emisión de actas de infracción automatizadas: tanto la Memoria de impacto normativo como la Exposición de Motivos del proyecto de Real Decreto parten de ella ${ }^{15}$. Algunos indicios literales podrían apuntar en esta misma línea: al constreñirse las nuevas decisiones automatizadas al "ámbito de la Administración General del Estado" tanto en la rúbrica del futuro Capítulo IX como en el arranque del futuro art. 43 parece estarse pensando exclusivamente en la proyección de las actas automatizadas en ámbitos de competencia estatal. Por otro lado, algunos ilícitos administrativos en materia de seguridad social son idóneos para la activación automatizada del procedimiento sancionador. Señaladamente en el terreno de la recaudación, cabe pensar en una fácil penetración de los algoritmos habida cuenta su intensa digitalización. No resulta difícil aceptar que las reclamaciones de deuda (art. 33 LGSS), que ya están automatizadas, den vida con facilidad a actas igualmente automatizadas con base en el art. 22.3 LISOS.

Sin embargo, nada en el nuevo texto del art. 53.1.a) LISOS nos indica que este tipo de actuaciones automatizadas solo sea posible en esta materia; $\mathrm{y}$ los indicios en el futuro reglamento tampoco parecen concluyentes. Seguramente, la referencia a la Administración General del Estado no delimita el ámbito de actuación de las actas automatizadas, sino que acaso se relaciona simplemente con la ubicación del Organismo Estatal Inspección de Trabajo y Seguridad Social en su ámbito. De este modo, y sin perjuicio de su conexión genética y funcional con la recaudación, nada parece impedir que las actas automatizadas puedan ser utilizados en otros espacios del procedimiento sancionador en el orden social.

${ }^{14}$ En esta línea, véase el comunicado hecho público por la Junta del Sindicato de Inspectores de Trabajo y Seguridad Social el pasado 26 de enero de 2021 (https://www.asnala.com/media/docs/corona/573-SITSS-AUTOMATIZACION-SANCIONES.pdf; acceso 15 de febrero de 2021).

${ }^{15}$ En las consideraciones preliminares del proyecto de Real Decreto, por el que se modifica el Reglamento general sobre procedimientos para la imposición de sanciones por infracciones de Orden Social se afirma:

En relación con ello, el análisis masivo de datos para la detección de fraude permite conocer la existencia de posibles incumplimientos de los sujetos obligados, especialmente en materia de Seguridad Social, que provocan perjuicios a los trabajadores afectados y a la propia administración de la Seguridad Social. En ocasiones, la constatación de estos incumplimientos no requiere la intervención directa de ningún funcionario del Sistema de Inspección de Trabajo y Seguridad Social. Partiendo de esta base, se pone de manifiesto la necesidad de automatizar, en casos concretos, la actividad de la Inspección de Trabajo para poder actuar ante tales incumplimientos.

La conexión entre decisiones automatizadas en el procedimiento administrativo sancionador y los incumplimientos en materia de recaudación de la Seguridad Social puede verse también en la página 4 Memoria del análisis de impacto normativo del citado proyecto (https://www.mites.gob.es/ficheros/participacion/historico/informacion-publica/2021/ MAIN-RD-sancionesSS_20210118.pdf; acceso: 16 marzo 2021) 
En cuanto a los efectos, hemos visto que las nuevas actas extendidas en el marco de procedimientos automatizados tienen, como las ordinarias, el sentido de iniciar el procedimiento sancionador. Pero la principal cuestión es si despliegan también su efecto probatorio típico: la presunción de certeza. La cuestión se presta a la discusión. Es probable que haya que excluir este efecto en atención al lugar en el que han sido reguladas, el art. 53.1.a), sin que se haya producido modificación alguna en los requisitos legales y reglamentarios para que un acta de la Inspección adquiera tan importante efecto. Recuérdese, en este sentido, que la normativa vigente exige para que se produzca la constatación de los hechos por los funcionarios de la Inspección (arts. 53.2 LISOS, 23.I LITSS y 15 RPSOS), de modo que solo los hechos "comprobados directamente" por el funcionario actuante adquieren esta eficacia probatoria (STC 76/1990, de 26 de abril, f.j. 8.B]). En fin, el hecho de que, en los trabajos preparatorios de la futura reforma reglamentaria, las actas automatizadas mantengan una regulación separada apuntaría también en esta dirección, pues quedarían nítidamente al margen de las extendidas por funcionarios ${ }^{16}$. Por eso, ya se ha sostenido que las actas automatizadas carecen de presunción de certeza siendo meras pruebas documentales, cuya eficacia probatoria dependerá de la calidad de los datos que se hayan manejado ${ }^{17}$.

Acaso, sin embargo, la cuestión no pueda zanjarse de forma tan rápida. En primer lugar, debe recordarse que el fundamento de la presunción de certeza se ha encontrado tradicionalmente "en la imparcialidad y especialización, que, en principio, debe reconocerse al Inspector actuante" y que, por otro lado, la misma "alcanza no sólo a los hechos que por su objetividad son susceptibles de percepción directa por el Inspector, o a los inmediatamente deducibles de aquéllos, sino también a aquellos hechos que resulten acreditados por medios de prueba consignados en la propia acta, como pueden ser documentos o declaraciones incorporadas a la misma" ${ }^{18}$. Si lo pensamos fríamente, no parece existir ningún problema en aceptar que los rasgos de "imparcialidad y especialización" pueden ser predicados de un algoritmo, incluso en mayor medida que de una persona física. Es de notar, por otro lado, que las futuras reglas reglamentarias no arrojan luz adicional sobre este aspecto, a pesar de su capital importancia; y, sin embargo, sí que dejan claro que el acta automatizada, en línea con lo que se exige a los funcionarios, debe recoger los medios de prueba que el algoritmo haya utilizado para su extensión ${ }^{19}$. Por último, aunque no por ello menos importante, no puede perderse

\footnotetext{
${ }^{16}$ Según el proyectado art. 44 RGPSOS las actas de infracción automatizadas "deberán contener los requisitos del apartado 1 del artículo 14, a excepción de los previstos en los párrafos b) y g)". Si esta última se refiere a la identificación del funcionario actuante y a su firma, que son sustituidas en las actuaciones automatizadas por el Sello Electrónico Cualificado de la Inspección de Trabajo y Seguridad Social (futuro art. 44.3 RGPSOS), aquella alude precisamente a "los hechos comprobados por el funcionario actuante, con expresión de los relevantes a efectos de la tipificación de la infracción, los medios utilizados para la comprobación de los hechos que fundamentan el acta, y los criterios en que se fundamenta la graduación de la propuesta da sanción; asimismo, consignará si la actuación ha sido mediante visita, comparecencia o por expediente administrativo". A falta de estas menciones, no cabría admitir que surgiera la presunción de certeza por imperativo de las propias reglas reglamentarias (art. 15 RGPSOS).

${ }^{17}$ IZQUIERDO, “La IA en la inspección y sanción” cit., aproximadamente desde 29’20”.

18 Se trata de un lugar común en la jurisprudencia que aplica la presunción de certeza. Véase, por ejemplo, SSTS cont. 8 mayo 2000, rec. 287/1995, o 4 diciembre 2009, rec. 292/2008, con cita de otras muchas. Esta doctrina, firmemente asentada en el orden contencioso, ha sido asumida por el orden social tras la asunción de competencias en este terreno. Véase STSJ Cataluńa social 13/2018, 23 abril, con cita de otras muchas, de la que se extrae el fragmento reproducido en el texto.

${ }^{19}$ Sin embargo, el proyectado art. 44.2 establece
}

Las actas habrán de reflejar los hechos comprobados como resultado de la actuación administrativa, con expresión de aquellos que sean relevantes a efectos de la tipificación de la infracción, los medios utilizados para la comprobación de los hechos que fundamentan el acta y la indicación expresa de que se trata de una actuación administrativa automatizada iniciada mediante expediente administrativo. 
de vista que la eficacia probatoria privilegiada puede entrar por la puerta de atrás, en caso de que, sobre la base de las alegaciones emitidas por el interesado, se produzca la intervención personal de un funcionario. Esta se concreta, según el proyectado art. 46.3 RGPSOS, mediante un "informe" en el que, a la vista de la evolución normativa ${ }^{20}$, podría ser fácil encontrarla si aquel ratificase los hechos delimitados en vía automatizada.

\section{Gestión administrativa automatizada y derechos individuales}

No cabe poner en cuestión, desde luego, que las decisiones automatizadas se irán incorporando de forma creciente a la gestión administrativa. La de la seguridad social o la intervención administrativa en las relaciones laborales no pueden ser ajenas a esta realidad. En este contexto, parece claro que la cuestión no es tanto discutir su presencia, que a buen seguro se ha de producir antes o después, sino determinar las garantías que la deben rodear. Se trata de encontrar, en otras palabras, un punto en el que el incremento de eficiencia administrativa que su incorporación posibilita no implique sacrificios irrazonables o desproporcionados de las expectativas de los ciudadanos. Lo relevante es, así, la discusión de los límites. Se trata de una idea común en la doctrina jurídicoadministrativa que destaca las obvias ventajas que presenta el recurso a la inteligencia artificial en la gestión pública pero también los desafíos que la misma plantea, habida cuenta que sabemos que los algoritmos evolucionarán con autonomía como consecuencia del desarrollo de los mecanismos de aprendizaje profundo y se transformarán paulatinamente en "cajas negras", de dinámica incompresible para la inmensa mayoría de los ciudadanos ${ }^{21}$. Se hace preciso, en este contexto, hallar un punto de equilibrio que permita "dotar de seguridad jurídica a las distintas aplicaciones y usos de la inteligencia artificial en las administraciones públicas" y a la vez fomente la innovación y garantice "la rápida adaptación a la evolución vertiginosa de la inteligencia artificial" 22 . La búsqueda de este punto de equilibrio es, por lo demás, particularmente necesario en supuestos como los que han centrado nuestra atención a raíz de la aprobación del RDL 2/2021. En razón de su temática, la inteligencia artificial muestra ahora su cara menos amable: como consecuencia de la reforma ya no actuará en el terreno del reconocimiento ágil de prestaciones, sino en el ámbito de las decisiones recaudatorias y sancionadoras.

En atención a todo ello, parece necesario terminar estudiando los posibles límites y garantías. A estos efectos, creo que cabe adoptar dos puntos de vista diferentes. De entrada, en un plano subjetivo, podemos verlo desde la perspectiva de los derechos individuales. A través de este primer análisis, cabría identificar remedios al alcance de los ciudadanos en relación con las decisiones administrativas automatizadas que les afecten. Por otro lado, en un terreno más objetivo, es preciso atender a posibles requisitos de funcionamiento de los algoritmos en la gestión pública. Se trata ahora de poner el acento en su control preventivo.

Acaso la identificación en el acta del origen de los datos, junto con la aplicación supletoria del Cap. III RGPSOS -que incluye el art. 15-, pudieron conducir a la aplicación de la presunción de certeza.

${ }^{20}$ Inicialmente solo se equiparaban los informes "en los supuestos concretos a que se refiere la Ley Ordenadora de la Inspección de Trabajo y Seguridad Social, consecuentes a comprobaciones efectuadas por la misma, sin perjuicio de su contradicción por los interesados en la forma que determinen las normas procedimentales aplicables" (art. 53.2.II). Pero el listado establecido en la disp. adic. $4^{\mathrm{a}}$ Ley 42/1997 ha desaparecido de modo que la LITSS vigente parece haber ampliado la equiparación de la eficacia probatoria especial a todos los informes (cfr. art. 23.II).

${ }^{21}$ CERRILLO, "El impacto de la inteligencia artificial" cit., pp. 3 ss.

${ }^{22}$ CERRILLO, "El impacto de la inteligencia artificial” cit., p. 8. En línea parecida, CORTÉS, "Algoritmos y algunos retos jurídico-institucionales” cit, p. 56. 


\subsection{Derechos relacionados con la protección de datos personales}

Abordando la primera perspectiva, nuestra atención se vuelve de inmediato a la regulación de las decisiones automatizadas en el marco de la normativa de protección de datos. Sin embargo, en su vigente configuración no permite alcanzar resultados relevantes. Es verdad que, como regla general, este tipo de decisiones están prohibidas por el Reglamento (UE) 2016/679 del Parlamento Europeo y del Consejo, de 27 de abril de 2016, relativo a la protección de las personas físicas en lo que respecta al tratamiento de datos personales y a la libre circulación de estos datos -en adelante, RGPD-. Su art. 22.1 establece, en efecto, que "todo interesado tendrá derecho a no ser objeto de una decisión basada únicamente en el tratamiento automatizado, incluida la elaboración de perfiles, que produzca efectos jurídicos en él o le afecte significativamente de modo similar". Pero no es menos cierto que, en relación con el tema que nos ocupa, esta regla tiene un efecto muy inferior al que resulta de la lectura rápida de su enunciado. De entrada, en el ámbito concreto en el que se mueven estas reflexiones, es preciso tener en cuenta los límites derivados de su titularidad: el derecho a la protección de los datos únicamente resulta predicable de las personas físicas (cfr. art. 1 RGPD) lo que excluiría la aplicación de esta norma a la mayoría de las empresas por tener la condición de personas jurídica. No cabe negar que los datos sobre los que se basarán las actuaciones automatizadas en materia de gestión de la Seguridad Social o en el marco del derecho administrativo sancionador en el orden social serán normalmente datos personales de los trabajadores en el sentido del art. 4.1 RGPD. Pero, en atención a este mismo precepto, son estos los interesados que no pueden quedar sujetos, en principio, a decisiones automatizadas con base en el tratamiento de sus datos. El empresario persona jurídica, destinatario normal de las actuaciones recaudatorias o sancionadoras, no sería pues el interesado al que se refiere el art. 22.1 RGPD ${ }^{23}$.

En todo caso, y sobre todo, la prohibición de las decisiones automatizadas admite excepciones, entre las que se incluye la posibilidad de que estén autorizadas "por el Derecho de la Unión o de los Estados miembros que se aplique al responsable del tratamiento" (art. 22.1.b]). En este último terreno, el art. 23 RGPD permite por vía legislativa, y con ciertas condiciones, introducir limitaciones a los diferentes derechos y obligaciones reconocidos, entre otros, en el citado art. 22 siempre que se busque con ello alcanzar alguna de las finalidades establecidas en el precepto. Y entre ellas se incluyen "otros objetivos importantes de interés público general de la Unión o de un Estado miembro, en particular un interés económico o financiero importante de la Unión o de un Estado miembro, inclusive en los ámbitos fiscal, presupuestario y monetario, la sanidad pública y la seguridad social" (letra e]), así como una "función de supervisión, inspección o reglamentación vinculada, incluso ocasionalmente, con el ejercicio de la autoridad pública" en diferentes casos entre los que se incluyen los contemplados en la citada letra e) (letra h]).

Por supuesto, el hecho de que sean admisibles no implica que no queden sujetas a condicionantes. Es verdad que los establecidos en el art. 22.3 RGPD -“el derecho a obtener intervención humana por parte del responsable, a expresar su punto de vista y a impugnar la decisión" - no resultan directamente aplicables. Sin embargo, sí que lo son la prohibición de incorporar al tratamiento datos de categorías especiales (art. 22.4) y, sobre todo, los criterios generales que condicionan las limitaciones de derechos y obligaciones conforme al art. 23 RGPD. Las decisiones administrativas automatizadas presuponen el tratamiento de datos sujetos a las reglas y principios generales (arts.

\footnotetext{
${ }^{23}$ Sobre la base del carácter personal de los datos tratados en las nuevas actas automatizadas, se ha sostenido la aplicación del art. 22 RGPD por IZQUIERDO (“La IA en la inspección y sanción” cit., aproximadamente desde 23' 20”. Más correcto me parece, sin embargo, la aproximación de TODOLÍ, "Retos legales del uso del big data” cit., pp. 318 ss., que limita la posible proyección del art. 22 RGPD a empresarios que sean personas físicas, autónomos y profesionales a los que habría que añadir, como se ha indicado en el texto, a los beneficiarios de prestaciones de la Seguridad Social.
} 
5 ss. RGPD) y no puede establecerse cualquier limitación que los ponga en peligro ni estas pueden introducirse de cualquier modo. Por ello, las decisiones automatizadas que se introduzcan ha de respetar "en lo esencial" los derechos y libertades fundamentales y constituir "una medida necesaria y proporcionada en una sociedad democrática” para alcanzar alguna de las finalidades descritas en el propio precepto (art. 23.1); de otro, la medida legislativa que la autoriza debe incluir una serie de disposiciones específicas que den cumplimiento a los distintos aspectos contenidos en el art. 23.2.

A la postre, pues, parece claro que, en relación con el tema que nos ocupa, no cabe esperar mucho de la configuración actual de la regulación europea de las decisiones automatizadas. La doctrina administrativa que se ha ocupado del tema ha insistido en esta línea, en que no se ha de esperar de aquella una aportación espectacular pues su finalidad no es tanto la protección de los derechos individuales como la constitución y regulación de un mercado único en relación con los datos ${ }^{24}$. En este contexto, una vez cumplidas las escasas garantías y los mínimos formales impuestos por las normas que hemos analizado, habrá que admitir que las decisiones administrativas automatizadas superan con creces las previsiones del RGPD. Ello nos obliga a mirar hacia otros derechos individuales menos sofisticados, de corte más tradicional.

\subsection{Los derechos «tradicionales»}

Los que podrían estar en juego protegerían, con toda probabilidad, al conjunto de los posibles afectados por procedimientos recaudatorios o sancionadores, independientemente de que fueran personas físicas o jurídicas. En este sentido, no parece necesario reconstruir a nivel teórico el debate sobre la titularidad de los derechos fundamentales de las personas jurídicas ${ }^{25}$, habida cuenta de que la jurisprudencia constitucional ${ }^{26}$ es bastante clara respecto de alguno de los derechos «tradicionales» que pueden ser puestos en riesgo por la intervención de algoritmos en la adopción de decisiones administrativas automatizadas. Estoy pensando, claro está, en los derechos de carácter relacional y procedimental, esto es los vinculados al principio de igualdad (art. $14 \mathrm{CE}$ ), a las distintas facetas del proceso debido y a las garantías del ejercicio del poder sancionador (arts. 24 y $25 \mathrm{CE}$ ).

Una de las cuestiones más analizadas en relación con las decisiones automatizadas es el de la aparición de discriminaciones algorítmicas ${ }^{27}$. Aun cuando en teoría, los algoritmos pueden ser programados para ser perfectamente objetivos en la toma de decisiones, en su funcionamiento real se detecta como las decisiones que adoptan pueden incorporar sesgos discriminatorios. Ello puede deberse

${ }^{24}$ BOIX PALOP, A., "Los algoritmos son reglamentos: la necesidad de extender las garantías propias de las normas reglamentarias a los programas empleados por la Administración para la adopción de decisiones”, Revista de Derecho Público: Teoría y Método, vol. 1 (2020), pp. 223 ss, en pp. 244 ss.

${ }_{25}$ Para la aproximación teórica, véanse, por ejemplo, ALFARO ÁGUILA-REAL, J., "Las personas jurídicas no tienen derechos fundamentales: de ninguna clase", I y II, Almacén de Derecho 17 mayo y 8 junio 2020, radicalmente contrario a aceptar la titularidad por las personas jurídicas. Una propuesta interpretativa diferente en GÓMEZ MONTORO, A.J., "La titularidad de derechos de las personas jurídicas: un intento de fundamentación", Revista Española de Derecho Constitucional 65(2002), pp. 49 ss.

${ }^{26}$ Se trata de derechos cuya proyección sobre las personas jurídicas no se ha puesto en cuestión, sin perjuicio de la existencia de matices, sobre todo en el caso de la igualdad. Cfr. GÓMEZ MONTORO, A.J., "La titularidad de derechos fundamentales por personas jurídicas (Análisis de la jurisprudencia del Tribunal Constitucional Español)", Cuestiones constitucionales 2(2000), pp. 23 ss.; BASTIDA FREIJEDO, F.J., et al., Teoría general de los derechos fundamentales en la Constitución Española de 1978, Madrid (Tecnos), 2004, pp. 84 ss.; o DÍEZ-PICAZO, L.M., Sistema de derechos fundamentales, 2a ed., Madrid (Thomson/Civitas), 2005, pp. 133 ss.

${ }^{27}$ SAEZ LARA, C., "Algoritmos y discriminación en el empleo: un reto para la normativa antidiscriminatoria", Revista Española de Derecho del Trabajo, 232(2020) o SORIANO AZNAR, A., "Decisiones automatizadas y discriminación: aproximación y propuestas generales”, Revista General de Derecho Administrativo 56 (2021). 
a defectos en su programación o a las dificultades para eliminar los sesgos existentes en el inabarcable mundo del big data. Sea como sea, estos fenómenos se producen y suponen la posible adopción automática de decisiones discriminatorias ${ }^{28}$. Y no hay ninguna razón para pensar que este tipo de sesgos puedan igualmente aparecer en las decisiones administrativas automatizadas: son buena muestra de ello las prevenciones que se encuentran detrás del reciente pronunciamiento de un tribunal holandés en relación con SYRI, el sistema de inteligencia artificial Systeem Risicoindicatie establecido para detectar fraudes, entre otros aspectos, en la percepción de subsidios y beneficios sociales ${ }^{29}$.

Ciertamente, los perjudicados por los sesgos existentes en la programación o los datos tienen a su disposición la tutela antidiscriminatoria de carácter general. En otras palabras, el solo riesgo de su existencia no es suficiente para impedir la utilización de decisiones automatizadas en la gestión administrativa. Debe tenerse, en cuenta, sin embargo, los especiales problemas que plantea la efectiva defensa en estos casos. A los de carácter general, se añaden otros específicos del contexto en el que se producen estos nuevos sesgos discriminatorios. En el ámbito del big data, el efectivo conocimiento de la existencia de casos resueltos en sentido diferente puede resultar muy complejo o directamente imposible. Por otro lado, la discusión a nivel individual del funcionamiento del proceso que conduce a una decisión automatizada resulta también compleja, si no imposible ${ }^{30}$.

Por otro lado, en las decisiones administrativas automatizadas el algoritmo sustituye al procedimiento administrativo y, con ello, altera sustancialmente las garantías tradicionalmente establecidas para los administrados. Este tipo de decisiones aparece de forma directa, sin que en su formación se produzca interacción entre aquellos y el funcionario y autoridad competente. A su través, surgirá una decisión dotada de la eficacia privilegiada que le corresponda como acto administrativo, sin que exista contribución significativa del ciudadano. Así, por ejemplo, en el supuesto que nos ocupa, las nuevas actas automatizadas, todas las reglas sobre actuación inspectora (arts. $20 \mathrm{y}$, sobre todo, 21 LITSS; arts. 8 ss. RGPSOS) quedan sustituidas por el funcionamiento de la "caja negra" algorítmica. Por supuesto, no se trata de una cuestión secundaria puesto que la indicada eficacia privilegiada suele asociarse no solo con la naturaleza pública de la que entidad de la que emana el acto sino también con la vigencia del principio de contradicción antes de su emisión. En esta línea cabe traer a colación la STC 90/1994, de 17 de marzo, en la que se valoró el art. 23, apartado 3, de la entonces vigente LPL (actualmente, art. 23.7 LRJS). Se cuestionaba si la particular eficacia en el proceso que el precepto asignaba a las afirmaciones de hecho contenidas en el expediente se ajustaba o no a la tutela judicial efectiva; y el TC excluyó que el precepto resultara inconstitucional habida cuenta de que la "posibilidad de contradicción en la tramitación del procedimiento y, en concreto, en relación con las afirmaciones de hecho que consten en el expediente, así como la propia finalidad del FOGASA" lo justificarían suficientemente.

La preocupación por la sustitución de las garantías de los administrados por la recopilación y tratamiento de datos y la emisión de decisiones administrativas automatizadas se advierte en la decisión del Consejo Constitucional francés de 27 de diciembre de 2019 (2019-796 DC), en relación con el art. 154 de la Ley de presupuestos de $2020^{31}$, que posibilitaba que la autoridad fiscal

${ }^{28}$ Sobre las diferentes causas que lo producen, cfr. SORIANO “Decisiones automatizadas y discriminación” cit. , pp. 11 ss.

${ }^{29}$ Sobre el riesgo de que la discriminación algorítmica se extienda a la actuación de los poderes públicos, véase, en la doctrina laboral, MERCADER, "Algoritmos: personas y números” cit., p. 11. Para un análisis detallado del supuesto y la en COTINO HUESO, L., “SyRI, ¿̨a quién sanciono?» Garantías frente al uso de inteligencia artificial y decisiones automatizadas en el sector público y la sentencia holandesa de febrero de 2020”, La Ley Privacidad 4, mayo 2020

${ }^{30}$ En relación con las específicas dificultades de proyectar las reglas generales de tutela frente a la discriminación sobre las decisiones automatizadas, véase SORIANO “Decisiones automatizadas y discriminación” cit. , pp. 29 ss.

${ }^{31}$ Más detalles sobre esta resolución, así como una valoración crítica de la presencia de la inteligencia artificial al 
procediera a la recopilación y tratamiento de los datos existentes en las plataformas digitales con la finalidad de evitar la evasión tributaria. La resolución sobre su adecuación constitucional ha mirado de forma restrictiva las previsiones del precepto, declarando inconstitucional alguna de ellas por extralimitar las exigencias del principio de proporcionalidad -en la medida que hubiera permitido tratamientos de datos que no resultan estrictamente necesarios sino solo más cómodos (\$ 94$)$ - y haciendo mucho hincapié en las garantías establecidas, relacionadas con quién desarrolla el tratamiento, cómo se desarrolla y, sobre todo por lo que aquí interesa, el impacto real sobre los derechos de defensa de los ciudadanos. Es muy ilustrativa en este último punto la parte de la sentencia en que se valora que los datos indiciarios de la infracción fiscal se transmiten al organismo competente para su corroboración y valoración, sin que puedan iniciarse las actuaciones "sin una evaluación individual de la situación de la persona por parte de la administración, que no puede fundarse exclusivamente sobre los resultados del tratamiento automatizado". Y también que "los datos recogidos sólo pueden utilizarse contra la persona en el marco de un procedimiento de control... respetando el principio de contradicción y los derechos de defensa” (\$94).

El planteamiento suministra argumentos para discutir la introducción de decisiones automatizadas con carácter general y, particularmente, en los dos terrenos en los que se ha movido el RDL $2 / 2021$. No se olvide que estamos ante actos automatizados que gravan a las personas o implican la iniciación de actuaciones sancionadoras contra ellas; y que en este último caso existen posibilidades de entender que los hechos establecidos por la decisión automatizada ostenten un valor probatorio especial. No es posible por tanto descartar que se abra un conflicto con los derechos procesales y vinculados a la regularidad del ejercicio del poder sancionador (art. 24 y $25 \mathrm{CE}$ ). Desde mi punto de vista, sin embargo, no hay que simplificar en exceso el tema. El incremento de la eficacia administrativa es necesario y es, además, una finalidad constitucionalmente protegida (cfr. art. 103.1 $\mathrm{CE}$ ). En este contexto, cabe prever que se producirá una reinterpretación de los escollos al uso de las decisiones automatizadas que estamos analizado. En este sentido, el solo inicio automatizado de un procedimiento recaudatorio o sancionador no parece desproporcionado en todo caso. Más bien parece que debería ponderarse su razonabilidad en función de los datos que se hayan tomado en consideración y la capacidad del algoritmo para valorar el conjunto de las circunstancias relevantes. Por otro lado, los problemas relacionados con la contradicción pueden ser orillados, como se hace en los trabajados preparatorios de la reforma del RGPSOS, garantizando un sistema adecuado de revisión de la decisión automatizada. Al límite, si se asignara a las declaraciones fácticas de esta un valor probatorio reforzado, creo que acabaremos por asumir un cierto nivel de determinismo tecnológico insistiendo en la necesidad de calidad tanto en los datos como en la forma de diseñar el algoritmo. De hecho, como he apuntado más arriba, existe experiencia de actuaciones automatizadas en el campo del Derecho administrativo sancionador sin que, por lo que he podido ver, su funcionamiento haya sido cuestionado sobre la base de estas razones ${ }^{32}$.

servicio de la fiscalidad en CALDERÓN CARRERO, J.M., "El encuadramiento legal y límites del uso de herramientas de inteligencia artificial con fines de control fiscal. Análisis de la decisión del Consejo Constitucional francés de 27 de diciembre de 2019 (Décision n. ${ }^{0}$ 2019-796 DC), sobre la Ley de Presupuestos 2020", Revista de Contabilidad y Tributación. CEF, 444 (2020), pp. 119 ss. Véase también TODOLÍ, "Retos legales del uso del big data", cit. pp. 325 ss.

${ }^{32}$ Me refiero a los sistemas de control de infracciones de tráfico por control de velocidad e identificación por imagen que dan lugar a denuncias automatizadas de los que dan cuenta los repertorios (entre otras, SSJCA Ciudad Real-1 184/2018, 25 septiembre, Ciudad Real-2 30/2019, 11 febrero, o Murcia 268/2019, 11 diciembre; con anterioridad, STEDH 8 marzo 2012, Célice contra Francia, da cuenta ya de la presencia de estas decisiones en este ámbito). Aunque alguna aproximación ha conectado la creciente automatización del sistema sancionador en materia de tráfico con la "eliminación de todos los derechos y garantías constitucionales en los procedimientos sancionadores" (cfr. "Multas de tráfico: el hecho punible y su contraste con el hecho imponible. Notas al nuevo sistema de tramitación automatizada de multas de tráfico", editorial de la revista Tráfico y Seguridad Vial 194/2015), las cuestiones que se discuten en los Tribu- 


\section{El control de los algoritmos en el Derecho administrativo}

No existen, en definitiva, razones relacionadas con los derechos individuales de los administrados que impidan de forma general y abstracta el uso de algoritmos en la gestión recaudatoria de la Seguridad Social o en el procedimiento sancionador en el orden social. Sin embargo, no parece difícil asumir la existencia de riesgos en confiar estos temas - u otros de análoga significación- a decisiones automatizadas. Los posibles efectos sobre la ciudadanía de las actuaciones administrativas automatizadas serán, como mínimo, igual de intensos y, con toda probabilidad, más trascedentes que los derivados de su utilización en las relaciones de carácter privado. Desde este punto de vista, parece razonable pensar que las exigencias aplicables a los poderes públicos han de ser "necesariamente mucho mayores que las que se aplican a las relaciones inter-privatos, sin que sea necesario argumentar en exceso el por qué: baste recordar el carácter imperativo, la nota de coactividad, inherente a todo ejercicio de funciones públicas, máxime si hablamos del ejercicio de funciones de autoridad"33.

\subsection{La normativa sobre actuaciones administrativas automatizadas...}

Sin embargo, la atención dispensada por el legislador no ha sido consciente hasta ahora de esta circunstancia; antes al contrario, se ha movido en la línea de ignorarla, en el caso del europeo; o, en el caso del español, en la de ir disminuyendo las garantías inicialmente establecidas ${ }^{34}$. Ya hemos visto la limitada aplicación de las reglas del RGPD sobre decisiones automatizadas en el ámbito administrativo. Conviene ahora reparar en la anómala evolución regresiva que han sufrido las normas internas sobre el particular. A estos efectos, conviene reparar en los principales hitos normativos que se han producido en las dos últimas décadas.

La Ley 30/1992, de 26 de noviembre, de Régimen Jurídico de las Administraciones Públicas y del Procedimiento Administrativo Común, que, según su Exposición de Motivos, protagonizó la "abierta incorporación de las técnicas informáticas y telemáticas en la relación ciudadano-Administración”, incluyó en su versión original un art. 45, dedicado a la "incorporación de medios técnicos". Tras afirmar que las Administraciones Públicas impulsarían “impulsarán el empleo y aplicación de las técnicas y medios electrónicos, informáticos y telemáticos, para el desarrollo de su actividad y el ejercicio de sus competencias, con las limitaciones que a la utilización de estos medios establecen la Constitución y las Leyes" (apartado 1), preveía que "los programas y aplicaciones electrónicos, informáticos y telemáticos que vayan a ser utilizados por las Administraciones Públicas para el ejercicio de sus potestades, (habrían) de ser previamente aprobados por el órgano competente, quien deberá difundir públicamente sus características".

En la década siguiente, este último precepto fue derogado por la Ley 11/2007, de 22 de junio, de acceso electrónico de los ciudadanos a los Servicios Públicos, cuyo art. 39 establecía un régimen diferente para las decisiones automatizadas en el ámbito administrativo. En concreto, "en caso de actuación automatizada deberá establecerse previamente el órgano u órganos competentes, según los casos, para la definición de las especificaciones, programación, mantenimiento, supervisión y control de calidad y, en su caso, auditoría del sistema de información y de su código fuente. Asimismo, se indicará el órgano que debe ser considerado responsable a efectos de impugnación”.

nales se relacionan con aspectos concretos del funcionamiento de estos sistemas (cfr. SÁNCHEZ FERNÁNDEZ, B., "Cuestiones controvertidas en la jurisprudencia menor derivadas de la utilización de elementos automáticos en materia de sanciones de tráfico, Revista Aranzadi Doctrinal 2/2020).

${ }^{33}$ BOIX, "Los algoritmos son reglamentos" cit., p. 248.

${ }^{34}$ BOIX, "Los algoritmos son reglamentos" cit., pp. 223 ss. 
Esta regla ha pasado al apartado segundo del art. 41 Ley 40/2015, cuyo apartado primero contiene la definición de esta noción: "cualquier acto o actuación realizada íntegramente a través de medios electrónicos por una Administración Pública en el marco de un procedimiento administrativo y en la que no haya intervenido de forma directa un empleado público”.

Por último, el recientemente aprobado Reglamento de actuación y funcionamiento del sector público por medios electrónicos (RD 203/2021, de 30 de marzo) -en adelante, RSPME-, a pesar de su vocación de alcanzar "un marco regulatorio adecuado, tanto con rango de ley como con rango reglamentario, que garantizando la seguridad jurídica para todos los intervinientes sirva a los objetivos de mejorar la eficiencia administrativa para hacer efectiva una Administración totalmente electrónica e interconectada, incrementar la transparencia de la actuación administrativa y la participación de las personas en la Administración Electrónica y garantizar servicios digitales fácilmente utilizables", no dedica una excesiva atención a las actuaciones que nos interesan. Tras el reconocimiento de que "la tramitación electrónica de una actuación administrativa podrá llevarse a cabo, entre otras formas, de manera automatizada de acuerdo con lo previsto en el artículo 41 de la Ley 40/2015, de 1 de octubre" (art. 13.1), se limita a determinar la competencia para adoptar la decisión -"en el ámbito estatal la determinación de una actuación administrativa como automatizada se autorizará por resolución del titular del órgano administrativo competente por razón de la materia o del órgano ejecutivo competente del organismo o entidad de derecho público, según corresponda-, explícita la exigencia de publicación -“en la sede electrónica o sede electrónica asociada”-y, además del señalamiento de "los recursos que procedan contra la actuación, el órgano administrativo o judicial, en su caso, ante el que hubieran de presentarse y plazo para interponerlos", se abre la posibilidad, no contemplada expresamente en el art. 41.2 Ley 40/2015 "de que las personas interesadas puedan ejercitar cualquier otro que estimen oportuno" (art. 13.2). Asimismo, aparece como novedad respecto a este texto legal, la imposición a la resolución que decida la automatización de una determinada actuación, el establecimiento de las "medidas adecuadas para salvaguardar los derechos y libertades y los intereses legítimos de las personas interesadas".

\section{2. . y y sus insuficiencias}

En esta línea, la comparación entre las reglas que inicialmente abordaron el uso de las tecnologías de la información en los quehaceres administrativas permite observar una disminución de garantías en dos terrenos diferentes: el ámbito de aplicación de las reglas legales y la naturaleza de las que se establecen. En el primero terreno, hay que señalar la restrictiva evolución de la noción de decisión automatizada. Las reglas aprobadas inicialmente tenían un ámbito de aplicación mucho más amplio que las vigentes pues, como se ha indicado, se extendían a "los programas y aplicaciones electrónicos, informáticos y telemáticos" que fueran a ser "utilizados por las Administraciones Públicas para el ejercicio de sus potestades". Sin embargo, desde 2007, se introduce noción abiertamente restrictiva que requiere que, en la adopción del acto de que se trate, "no haya intervenido de forma directa un empleado público". Obviamente, este cambio de giro tiene una importante consecuencia: allá donde se detecte la intervención humana, desaparecerá todo control sobre el algoritmo pues no resultará de aplicación la regulación legal o reglamentaria. Ello explica, por ejemplo, que el análisis doctrinal haya admitido sin grandes objeciones la utilización de la inteligencia artificial en la detección de objetivos para la actuación inspectora, sobre la base de que, en último término, la decisión de abrirla o no depende del factor humano ${ }^{35}$. Es claro, sin embargo, que la definición legal de "actuación

${ }^{35}$ TODOLÍ, "Retos legales del uso del big data" cit., pp. 314 y 315. 
administrativa automatizada" incurra en un reduccionismo excesivo: a medida que se desarrolle la inteligencia artificial resultará más difícil aceptar que el empleado público que valida una acción esté en condiciones de explicar y, por tanto, de controlar las decisiones adoptadas por el algoritmo ${ }^{36}$.

Por otro lado, y, sobre todo, las garantías para la introducción de actuaciones automatizadas son estrictamente formales. De acuerdo con la literalidad del art. 41.2 Ley 40/2015 son únicamente subjetivas, relacionadas con la necesidad de establecer previamente "el órgano u órganos competentes, según los casos, para la definición de las especificaciones, programación, mantenimiento, supervisión y control de calidad y, en su caso, auditoría del sistema de información y de su código fuente" así como la del que deba "ser considerado responsable a efectos de impugnación", si bien, como he indicado, el precepto presupone la publicidad de la decisión, como acaba de confirmar el art. 13 RSPME. Fuera de estos dos aspectos, no existen límites objetivos ni procedimentales para las resoluciones de las Administraciones que acuerden automatizar alguna de sus actuaciones. En el primer sentido, no existe ningún tipo de delimitación de las cuestiones susceptibles de tratamiento automatizado por razón de la materia o en atención a la naturaleza y características de la decisión de que se trate. En el segundo, parece que el precepto abre un espacio libérrimo para la determinación del algoritmo: frente a la normativa anterior -que requería la difusión pública de las características de las aplicaciones-, no se prevé ahora criterio alguno en relación con al modo en que se determina el algoritmo que adoptará el acto automatizado ni se prevé nada con respecto a la forma en que puede procederse a la verificación de su funcionamiento. Tan graves carencias han sido denunciadas, como se expondrá a continuación, por la doctrina administrativa; y con toda probabilidad se encuentran detrás de la tímida inflexión que ha protagonizado el art. 13.2 RSPME. La admisión de la posibilidad de ejercitar cualquier otro recurso por las personas y la necesidad de establecer "medidas adecuadas para salvaguardar los derechos y libertades y los intereses legítimos de las personas interesadas" parecen mirar en la línea de incorporar algunas de las críticas y sugerencias que se han movido al art. 41.2 Ley 40/2015. Aunque a la vista de la vaguedad del inciso, hay que hacer un cierto esfuerzo para darse cuenta.

En este sentido, se ha insistido en la necesidad de extremar las precauciones en relación con la incorporación de decisiones automatizadas a los procedimientos administrativos. La utilización en este terreno de la inteligencia artificial implica suficientes riesgos como para afirmar la necesidad de aplicar un principio de precaución ${ }^{37}$. A partir de esta idea, y de las exigencias de transparencia que deben presidir la actuación administrativa, una extensa serie trabajos han señalado múltiples aspectos que permitirían ajustar las decisiones algorítmicos a los valores humanos. Los mismos incluyen desde las exigencias de depuración de los datos que pueden ser considerados, hasta la necesidad de aportación de una dimensión ética en el desarrollo de la inteligencia artificial, pasando por la exigencia de específicas valoraciones de riesgos, la necesidad de desarrollar pruebas en entornos seguros o la constitución de organizaciones específicas dedicadas a estas cuestiones ${ }^{38}$. Sin entrar en este terreno, creo que resulta interesante, a los efectos perseguidos en este trabajo, hacer hincapié en tres

${ }^{36}$ Por todos, VALERO TORRIJOS, J., "Las garantías jurídicas de la inteligencia artificial en la actividad administrativa desde la perspectiva de la buena administración”, Revista catalana de Dret Públic, 58(2019), pp. 81 ss. (p. 97). Para una crítica similar, en relación con la interpretación estricta que realizan las administraciones competentes en el ámbito fiscal, OLIVARES OLIVARES, B.D., "Transparencia y aplicaciones informáticas en la Administración tributaria”, Crónica Tributaria 174(2020), pp. 89 ss. (pp. 95 ss.).

${ }^{37}$ Por ejemplo, PONCE SOLÉ, J., "Inteligencia artificial, derecho administrativo y reserva de humanidad: algoritmos y procedimiento administrativo debido tecnológico", Revista General de Derecho Administrativo 50 (2019), pp. 28 ss. o BOIX, "Los algoritmos son reglamentos" cit., pp. 224 ss.

${ }^{38} \mathrm{Al}$ respecto, CERRILLO "El impacto de la inteligencia artificial en el Derecho Administrativo" cit., pp. 14 ss., CORTÉS, Algoritmos y algunos retos jurídico-institucionales” cit., pp. 58 ss. o PONCE SOLÉ, J., "Inteligencia artificial, derecho administrativo y reserva de humanidad: algoritmos y procedimiento administrativo debido tecnológico", Revista General de Derecho Administrativo 50 (2019), en pp. 48 ss. 
exigencias apuntadas por la doctrina que no se encuentran claramente establecidas en la regulación legal y reglamentaria aplicable.

En primer lugar, el principio de precaución parece imponer restricciones respecto de las decisiones que pueden ser objeto de automatización, tomando en consideración el desarrollo de la inteligencia artificial y también la naturaleza de la actuación administrativa de que se trate. El derecho comparado muestra, en este sentido, la prohibición de automatizar determinado tipo de decisiones, las que incorporen valoraciones discrecionales ${ }^{39}$; y en la reflexión teórica se ha apuntado a la necesidad de mantener una reserva de humanidad en estos $\operatorname{casos}^{40}$. En nuestro derecho vigente queda en manos de la propia Administración la determinación de los ilícitos en los que puede ser utilizada la inteligencia artificial. Cabe confiar en que la Administración actúe razonablemente; pero sería interesante que estuviera obligada a hacerlo.

Por otro lado, el principio de transparencia impone necesariamente abrir la posibilidad de verificar el funcionamiento interno del procedimiento automatizado. La sustitución de las normas legales de 1992 por las de 2007 propició que esta garantía quedará profundamente afectada pues, aunque el vigente art. 41.2 Ley 40/2015 alude a "la definición de las especificaciones, programación, mantenimiento, supervisión y control de calidad y, en su caso, auditoría del sistema de información y de su código fuente", referencia todos estos aspectos a la decisión del órgano competente para decidir que una determinada actuación pase a ser automatizada y no los constituye en objeto de una obligación de información para la Administración o un derecho de acceso para los interesados. La doctrina administrativista se ha movido en la línea de entender que este derecho de acceso a la información ha de ser reconocido, sin que sean convincentes los argumentos que suelen manejarse para rechazar su existencia o para justificar la reducción de su alcance: la protección de la propiedad intelectual y las propias dificultades de explicar sencillamente el funcionamiento de la inteligencia artificial ${ }^{41}$. En esta línea, a pesar de que en muchas ocasiones las resoluciones administrativas en las que se autorizan actuaciones administrativas automatizadas, se limitan a informar de su existencia, sin dar más explicación respecto al funcionamiento de las aplicaciones informáticas utilizadas que la función genérica a que la sirven, el Consejo de Transparencia y Buen Gobierno, en el marco del control derivado de la Ley 19/2013, ha considerado, sobre la base del derecho de acceso a la información pública (arts. 12 ss.) que la obligación informativa es más amplia ${ }^{42}$. El recientemente aprobado RSPME avanza en esta línea. Además de explicitar la necesidad de publicación de las resoluciones que autoricen actuaciones administrativas automatizadas (art. 13.2), se establece un contenido mínimo para la publicación: el "contenido" de toda sede electrónica incluye una "relación actualizada de las actuaciones administrativas automatizadas", cada una de las cuales

${ }^{39}$ Es la regla vigente en Alemania (cfr. BOIX, "Los algoritmos son reglamentos” cit., p. 231). No siempre las reglas comparadas recogen expresamente esta idea (algunas regulaciones en PONCE "Inteligencia artificial, derecho administrativo" cit., pp. 28 ss.).

${ }^{40}$ PONCE "Inteligencia artificial, derecho administrativo" cit., pp. 28 ss.

${ }^{41}$ A favor del acceso total, BOIX, "Los algoritmos son reglamentos" cit. pp. 254 ss. Algo más matizado, considerando que la información a suministrar ha de ser "accesible y limitada" -aunque se admite que se haya de ponderar el acceso pleno si es "determinante para luchar contra un acto administrativo ilegal", CHAVES, "Regreso al futuro" cit., p. 31. Sobre la necesidad de transparencia en el ámbito laboral, ). MOLINA NAVARRETE, C., “"Duelo al sol» (digital). ¿Un algoritmo controla mi trabajo? Sí; a tu empresa también”, Revista de Trabajo y Seguridad Social. CEF, 457 (2021), pp. 5 ss. (pp. 18 ss.).

${ }^{42}$ Se trata de cuestión planteada en el ámbito estrictamente tributario, en el que existe una norma específica que combina preceptos que responden al esquema de 1992 con otros que podrían vincularse al de 2007 (art. 96 Ley 58/2003, de 17 de diciembre, General Tributaria). La publicación es, no obstante, muy genérica (OLIVARES, “Transparencia y aplicaciones informáticas" cit., pp. 98 ss.). La resolución a la que se alude es la 825/2019 de 13 de febrero de 2020 . 
"se acompañará de la descripción de su diseño y funcionamiento, los mecanismos de rendición de cuentas y transparencia, así como los datos utilizados en su configuración y aprendizaje" (art. 11.1.j]). Queda por saber si esta información será suficiente para posibilitar el control efectivo por los afectados o si, por el contrario, si estos pueden aspirar a obtener informaciones adicionales para defender sus expectativas legítimas.

Una cuestión adicional de sumo interés es si las exigencias de publicidad o los derechos de acceso a la información admiten excepciones por razón de la materia. Con carácter general, varios de los ítems incluidos como "límites al derecho de acceso" por el art. 14.1 Ley 19/2013 pueden actuar como obstáculo para reconocerlo en supuestos como los que son objeto de este trabajo. En concreto, las letras e) y g) -respectivamente dedicadas a "prevención, investigación y sanción de los ilícitos penales, administrativos o disciplinarios" y "funciones administrativas de vigilancia, inspección y control"- permitirían excluir del indicado derecho las actuaciones automatizadas en materia recaudatoria o sancionadora en el ámbito social. En el marco de la normativa tributaria, existen en esta línea reglas reglamentarias que excluyen de toda publicidad aplicaciones y algoritmos relacionados con las actuaciones inspectoras (art. 170.7 Reglamento General de las actuaciones y los procedimientos de gestión e inspección tributaria y de desarrollo de las normas comunes de los procedimientos de aplicación de los tributos, aprobado por Real Decreto 1065/2007, de 27 de julio). Una parte de los analistas ha aceptado la corrección de este tipo de restricciones a las obligaciones informativas de las Administraciones con la finalidad de evitar la evasión fiscal ${ }^{43}$ o, por lo que a nosotros interesa, de eludir la acción de la Inspección de Trabajo o adoptar otras conductas estratégicas al respecto ${ }^{44}$. Sin embargo, existen tomas de postura más cautelosas que hacen hincapié en que una cosa es limitar el derecho de acceso en el caso de que estén en juego estos intereses jurídicos -que, en ningún caso, podría hacerse de forma absoluta (arg. ex art. 14.2 Ley 18/2013- y otra diferente eludir las concretas exigencias de transparencia del funcionamiento de la inteligencia artificial que imponen la "publicidad activa" de las características de funcionamiento del algoritmo ${ }^{45}$. Encontrar un punto de equilibrio en este concreto terreno es, probablemente, un serio desafío para la reflexión futura.

Un último aspecto, aunque no por ello menos importante, se relaciona con las garantías de la puesta en marcha de las actuaciones automatizadas. Como hemos visto, la normativa legal y reglamentaria vigente parte de la discrecionalidad de los entes administrativos a la hora de acordarla. De este modo, no existe ningún control previo que pueda prevenir las eventuales insuficiencias del diseño. Solo es posible reparar sus consecuencias a posteriori, mediante la discusión en vía administrativa o judicial de los concretos actos emitidos por el algoritmo. Sin embargo, como se ha comentado al analizar las actuaciones automatizadas desde la perspectiva de los derechos individuales, este control a posteriori puede ser extraordinariamente difícil o directamente imposible para los particulares afectados. Para evitar ese problema, se ha planteado la posibilidad de que los algoritmos que posibilitan la adopción de decisiones administrativas automatizadas deben ser tratados como reglamentos administrados. Se trata de una sugerente interpretación, cuya consecuencia inmediata es sujetar las resoluciones de los entes públicos previendo el recurso a actuaciones administrativas automatizadas al régimen de garantías que presiden la elaboración de las normas reglamentarias (arts. 128 ss. Ley 39/2015); y, adicionalmente, sujetarlas a otras reglas o principios generales que afectan los reglamentos, señaladamente la inderogabilidad singular (art. 37.1 Ley 39/2015) y la posibilidad de recurso directo, con independencia de su aplicación ${ }^{46}$.

\footnotetext{
${ }^{43}$ CHAVES, "Regreso al futuro" cit., p. 31.

${ }_{44}$ TODOLI, "Retos legales del uso del big data” cit., pp. 323 y 324.

${ }^{45}$ VALERO, "Las garantías jurídicas de la inteligencia artificial” cit., p. 89.

${ }^{46}$ BOIX, "Los algoritmos son reglamentos" cit., pp. 250 ss.
} 
Es verdad que la asimilación de los algoritmos a los reglamentos es objeto de discusión en la doctrina administrativista. Pero no lo es menos que, incluso quienes la rechazan, son partidarios de extender garantías similares a los procedimientos de introducción de actuaciones automatizadas ${ }^{47}$. La ventaja de la asimilación es que el procedimiento queda ya sujeto a los "principios de buena regulación" del art. 129 -que suministran criterios para resolver algunos de los problemas derivados de la magra regulación actual-y a las exigencias de "participación de los ciudadanos en el procedimiento de elaboración de normas con rango de Ley y reglamentos" contempladas en el art. 133 Ley 39/2015. Habida cuenta de los crecientes problemas que planteará la comprensión del funcionamiento de la inteligencia artificial y de sus sistemas de calidad, la existencia de un momento previo a la introducción de la actuación automatizada en el que las representaciones de los intereses colectivos puedan contrastarlo aparece como una exigencia ineludible. Como lo es, en fin, la posibilidad de que estas mismas representaciones, que cuentan con mayores medios, puedan llevar directamente ante los tribunales los algoritmos que puedan generar decisiones discriminatorias o ilegales por cualquier otra causa.

\section{Consideraciones finales}

Tras el análisis desarrollado, es el momento de volver a las novedades introducidas por el RDL 2/2021 respecto de las actuaciones automatizadas en materia social y proceder a su valoración. Su Exposición de Motivos alude, en relación con estas y las innovaciones conexas, a la necesidad de "actuar con la suficiente agilidad", a la adecuación del procedimiento administrativo "a las posibilidades que las nuevas tecnologías permiten" o a "garantizar la eficaz gestión de la acción protectora del sistema de la Seguridad Social"; y no puede ponerse en duda de que la extensión de las actuaciones automatizadas se mueve en esta línea. Pero, como indiqué más arriba, el preámbulo normativo insiste también en que este efecto se produce "sin reducción de las garantías jurídicas de los administrados", y esta segunda afirmación sí que suscita algunas objeciones.

Desde mi punto de vista, solo es cierta desde una perspectiva formal. Es, sin embargo, mucho más discutible si la valoramos desde un punto de vista material. La incorporación de algoritmos al procedimiento administrativo se adecúa, desde luego, a las reglas establecidas con carácter general, tanto en el ámbito europeo como en nuestro ordenamiento interno. Desde ese punto de vista, no se ha producido la indicada "reducción de las garantías jurídicas". Sin embargo, esta conclusión, a mi juicio, solo puede aceptarse si le damos un significado formal puesto que todo indica que el régimen jurídico vigente no integra, de verdad, un marco razonablemente protector de los intereses de los administrados en relación con la inteligencia artificial. Sabemos, en primer lugar, que decisiones automatizadas, en el sentido del art. 22 RGPD, ya se están utilizando con anterioridad, como puede comprobarse en las correspondientes sedes electrónicas. Pero, como hemos visto, la restrictiva noción de actuación administrativa automatizada las deja huérfanas de todo régimen jurídico. En segundo lugar, parece necesario delimitar adecuadamente los supuestos en los que procede recurrir a las actas automatizadas, en atención a la naturaleza de las infracciones y del desarrollo actual de la tecnología. Solo en este caso, según creo, se garantizaría adecuadamente que su introducción se produzca, según la aspiración expresada por el propio legislador, sin reducción de las garantías jurídicas de los administrados. Pero, como hemos visto, no existen en nuestro ordenamiento límites

${ }^{47}$ CHAVES, "Regreso al futuro de las Administraciones Públicas", pp. 11 ss. Véase también PONCE, "Inteligencia artificial, derecho administrativo y reserva de humanidad” cit., pp. 34 ss., que sostiene, sin embargo, la asimilación indicada en el texto. 
específicos al respecto. Por último, y no por ello menos importante, no parece existir suficiente transparencia en la implantación de las actuaciones automatizadas ni relación con la difusión de las características de los algoritmos que las posibilitan. El ordenamiento administrativo general no la garantiza. Pero no por ello deja de ser necesaria, sobre todo habida cuenta la difícil inserción en el sistema normativo previo con los consiguientes problemas interpretativos. En este contexto, es claramente retórica la "duda" que se ha planteado uno de los primeros comentarios del RDL 2/2021 sobre si su incorporación "no debería haber cobrado más protagonismo y haber estado dotada de una regulación más completa e integral”48.

Esta impresión se acentúa si tomamos en consideración dos circunstancias más. La primera, en la que no insistiré porque a estas alturas es una batalla perdida, se relaciona con la vía que se ha utilizado para instrumentar la reforma: la aprobación de un Decreto-Ley que, para más inri, constituye un buen ejemplo de norma ómnibus. En cuanto a la segunda, se relaciona con la manifiesta asimetría que se ha producido en la regulación de los algoritmos en el ámbito social según funcionen en el ámbito de las relaciones privadas o públicas. En este sentido, según parece, la nueva letra d) del art. 64.4 ET, introducida por el RDL 9/2021, de 11 de mayo, reconoce el derecho del comité de empresa a "ser informado por la empresa de los parámetros, reglas e instrucciones en los que se basan los algoritmos o sistemas de inteligencia artificial que afectan a la toma de decisiones que pueden incidir en las condiciones de trabajo, el acceso y mantenimiento del empleo, incluida la elaboración de perfiles". Nada parecido se ha previsto con los que utilizan las entidades administrativas competentes en materia social.

Se trata acaso de una situación provisional. En el momento de cerrar este trabajo se ha hecho público el proyecto de Reglamento europeo sobre Inteligencia artificial. Quizá su aprobación implicará la aparición de nuevas reglas que superen estas anomalías. Entre tanto, habría que ser más cuidadoso, habida cuenta los potentes riesgos que puede tener su utilización ${ }^{49}$.

${ }^{48}$ MERCADER, J.R., “Algoritmos: personas y números” cit.

${ }^{49}$ Cfr. las interesantes reflexiones de BELTRAN DE HEREDIA RUIZ, I., "Big data, algoritmos y actas de infracción automatizadas: ¿un nuevo paradigma en la imputación de responsabilidad en el procedimiento sancionador del orden social?", blog Una mirada crítica a las relaciones laborales, 29 abril 2021 (https://ignasibeltran.com/2021/04/29/ big-data-algoritmos-y-actas-de-infraccion-automatizadas-un-nuevo-paradigma-en-la-imputacion-de-responsabilidaden-el-procedimiento-sancionador-del-orden-social/). 